\title{
Effects of temperature and cellular interactions on the mechanics and morphology of human cancer cells investigated by atomic force microscopy
}

\author{
LI Mi $^{1,2}$, LIU LianQing ${ }^{1 *}$, XI Ning ${ }^{1,3^{*}}$, WANG YueChao ${ }^{1}$, XIAO XiuBin ${ }^{4}$ \\ \& ZHANG WeiJing ${ }^{4}$ \\ ${ }^{1}$ State Key Laboratory of Robotics, Shenyang Institute of Automation, Chinese Academy of Sciences, Shenyang 110016, China; \\ ${ }^{2}$ University of Chinese Academy of Sciences, Beijing 100049, China; \\ ${ }^{3}$ Department of Electrical and Computer Engineering, Michigan State University, East Lansing MI 48824, USA; \\ ${ }^{4}$ Department of Lymphoma, Affiliated Hospital of Military Medical Academy of Sciences, Beijing 100071, China
}

Received September 13, 2014; accepted May 6, 2015

\begin{abstract}
Cell mechanics plays an important role in cellular physiological activities. Recent studies have shown that cellular mechanical properties are novel biomarkers for indicating the cell states. In this article, temperature-controllable atomic force microscopy (AFM) was applied to quantitatively investigate the effects of temperature and cellular interactions on the mechanics and morphology of human cancer cells. First, AFM indenting experiments were performed on six types of human cells to investigate the changes of cellular Young's modulus at different temperatures and the results showed that the mechanical responses to the changes of temperature were variable for different types of cancer cells. Second, AFM imaging experiments were performed to observe the morphological changes in living cells at different temperatures and the results showed the significant changes of cell morphology caused by the alterations of temperature. Finally, by co-culturing human cancer cells with human immune cells, the mechanical and morphological changes in cancer cells were investigated. The results showed that the co-culture of cancer cells and immune cells could cause the distinct mechanical changes in cancer cells, but no significant morphological differences were observed. The experimental results improved our understanding of the effects of temperature and cellular interactions on the mechanics and morphology of cancer cells.
\end{abstract}

atomic force microscopy, mechanics, cancer cell, temperature, cellular interactions

Citation: $\quad$ Li M, Liu LQ, Xi N, Wang YC, Xiao XB, Zhang WJ. Effects of temperature and cellular interactions on the mechanics and morphology of human cancer cells investigated by atomic force microscopy. Sci China Life Sci, 2015, 58: 889-901, doi: 10.1007/s11427-015-4914-4

The past decade has seen substantial growth in the studies on how changes in the biomechanical and biophysical properties of cells influence, and are influenced by, the onset and progression of many human diseases [1], including cancer [2], malaria [3], diabetes [4], osteoarthritis [5], and asthma [6]. Physiological changes within the cells are often accompanied by physical and mechanical changes [7], which are crucial for the cells to adapt to the dynamically

*Corresponding author (email: lqliu@ sia.cn; xin@egr.msu.edu) changing environments. The studies on cell lines and biopsy tumor tissues have shown that cancer cells are softer than normal cells [8] and the stiffness of cancer cells is directly related to their metastatic potential [9]. Recently, a comprehensive study on human breast tissues has shown that cell mechanics is an effective biomarker that can identify the different stages (normal tissue, benign lesion and invasive cancer) in the process of cancer development [10]. Thus, it is expected that the studies of cell mechanics will have a significant impact on cancer diagnosis and treatment. 
From the medical perspective, it may be possible to alter the mechanical properties of cancer cells, either through pharmacological inhibition or activation of proteins affecting cell mechanics, so that the mechanical properties of cancer cells are not optimal for stromal invasion and intravasation [11]. Such drugs would probably not cure by killing cancer cells, but may effectively hinder the propagation of the neoplasm [8]. However, in order to achieve this objective, more investigations are needed to let us have an in-depth and detailed understanding of the role of cell mechanics in cellular physiological activities.

In the past decade, atomic force microscopy (AFM) has emerged as an excellent tool for measuring the mechanical properties of single living cells in aqueous conditions. Studies have shown that the obtained Young's moduli of cells by AFM are dependent on several factors, such as the depth of indentation, the loading rate of tip, the position and time of cell poking, and the properties of substrates used for cell growth [12]. In recent years, researchers [13,14] have shown that temperature can also influence the cell stiffness. However, it is still unclear whether the effect of temperature on cell stiffness is a universal phenomenon for all types of cells. Besides, we know cancer cells interact with other cells (e.g., cancer-associated fibroblasts, vascular endothelial cells, and immune cells) to form a solid tumor during oncogenesis [15]. Currently it is unknown whether the interactions between cancer cells and other cells in the micro-environments will cause the changes of cell mechanical properties.

In this article, temperature-controllable AFM was applied to quantitatively investigate the mechanical properties of six types of cells (Raji, Jurkat, normal while blood cells, MCF-7, HeLa, and A549) at different temperatures (room temperature and $37^{\circ} \mathrm{C}$ ) to comprehensively analyze the effects of temperature on cell mechanics. The morphological changes in cells at different temperatures were also observed. The effects of cellular interactions on the mechanics of cancer cells were investigated by measuring the mechanical properties of three types of human cancer cells (MCF-7, HeLa, and A549) which were co-cultured with two types of immune cells (Raji and Jurkat). AFM imaging was also carried out to observe the morphological changes in cancer cells after being co-cultured with immune cells.

\section{Materials and methods}

\subsection{Cell culture}

Cell lines used in this study were obtained from the Affiliated Hospital of the Military Medical Academy of Sciences (Beijing) and the Institute Pasteur of Shanghai Chinese Academy of Sciences (Shanghai). Raji cells (human lymphoma B cell line), Jurkat cells (human leukemic $\mathrm{T}$ cell line), MCF-7 cells (human breast cancer cell line), HeLa cells (human cervical cancer cell line) and A549 cells (hu- man lung cancer cell line) were cultured in RPMI-1640 (Thermo Scientific Hyclone, USA) containing 10\% fetal bovine serum and $1 \%$ penicillin-streptomycin solution at $37^{\circ} \mathrm{C}\left(5 \% \mathrm{CO}_{2}\right)$. Peripheral blood was obtained from the healthy volunteers and treated by anticoagulants. Raji and Jurkat cells were cultured in flasks. MCF-7, HeLa, and A549 cells were cultured in Petri dishes. Cells were cultured for $24 \mathrm{~h}$ before experiments.

\subsection{Sample preparation}

Raji cells (Jurkat cells) were harvested by centrifuging at $500 \times g$ for 5 min. The harvested Raji (Jurkat) cells were dropped onto the glass slides which were previously coated by a layer of poly- $L$-lysine. The role of poly- $L$-lysine was attaching cells to the slides by electrostatic adsorption. Then the glass slides were placed in a Petri dish containing cell culture medium. The blood cells stratified after being placed in a centrifuge and then we could obtain the white blood cells from the junction of red blood cells (at the bottom of the centrifuge) and plasma (at the top of the centrifuge). White blood cells were then dropped onto the poly- $L$-lysinecoated glass slides which were then placed in a Petri dish containing cell culture medium. MCF-7, HeLa and A549 cells can naturally grow on the Petri dishes. After putting the Petri dishes to the sample stage, AFM indenting and imaging experiments were performed on cells.

The process of cellular co-culture was following. (i) Human cancer cells (MCF-7, HeLa and A549) were harvested by trypsin digestion. (ii) The harvested cells were pipetted into two fresh Petri dishes. One Petri dish was used for co-culture group and the other Petri dish was used for control group. (iii) Raji cells (or Jurkat cells) were added into one of the Petri dish (the co-culture group). (iv) Cell culture medium was added into the two Petri dishes and then the Petri dishes were incubated at $37^{\circ} \mathrm{C}\left(5 \% \mathrm{CO}_{2}\right)$ for $24 \mathrm{~h}$. (v) After the incubation, Petri dishes were taken out of the $\mathrm{CO}_{2}$ incubator and placed on the sample stage for AFM experiments.

\subsection{AFM system and probe}

Temperature-controllable AFM (Figure 1) was used in this study. Figure $1 \mathrm{~A}$ is the schematic diagram and Figure $2 \mathrm{~B}$ is the photograph of the temperature-controllable AFM. The Bioscope Catalyst AFM (Bruker, USA) was set on an inverted microscope (Nikon, Japan). Petri dishes containing cells were placed on the heating plate which was linked to a temperature controller (LakeShore Cryotronics, Inc., USA). With this system, we can perform AFM experiments on living cells at different temperatures. The type of AFM probe used in this study was MLCT (Bruker, USA) and the nominal spring constant of the cantilever used was $0.01 \mathrm{~N} / \mathrm{m}$. Force curves were obtained on the bare area of the substrate to calibrate the deflection sensitivity of the 


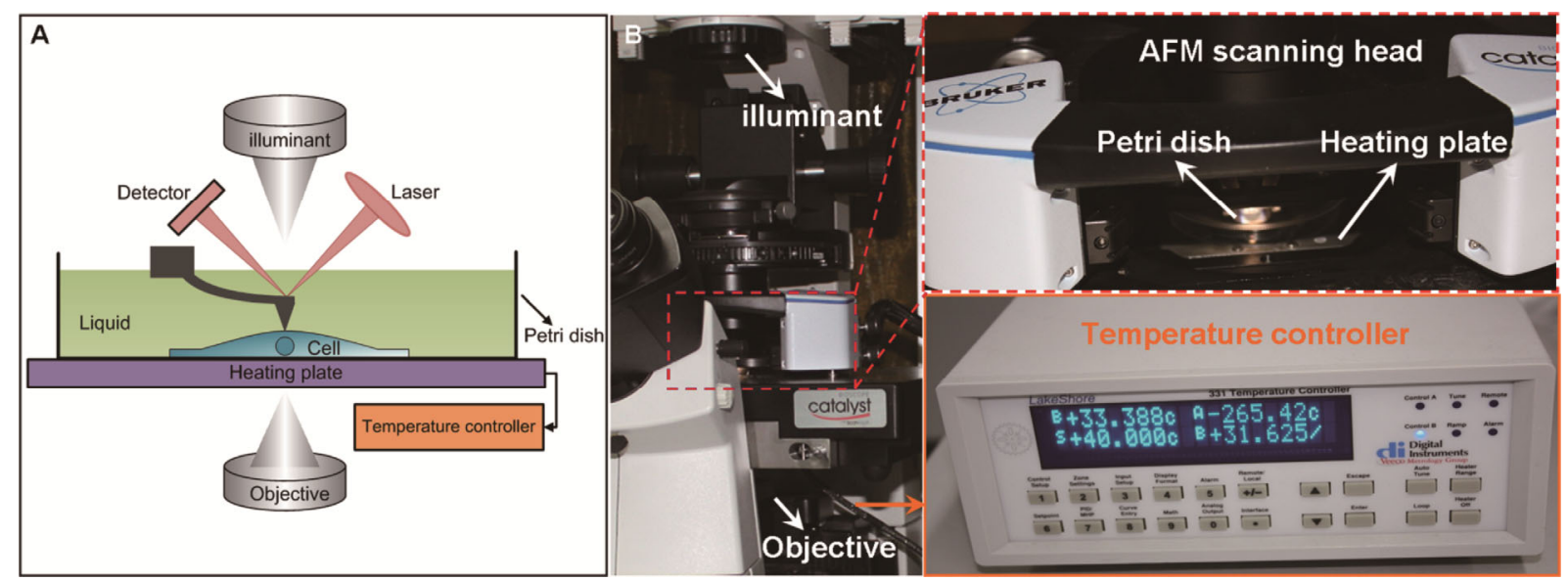

Figure 1 Temperature-controllable AFM experimental system. A, Schematic diagram. B, Photograph of the system. Cells were grown in the Petri dishes which were placed on a heating plate. There was a small hole in the heating plate (not shown in the schematic diagram). The optical light passes through the hole to obtain optical images of the cells.

cantilever and then the exact spring constant of the cantilever was calibrated by using the thermal tune module of AFM.

\subsection{AFM imaging and indenting}

Under the guidance of optical microscopy, AFM tip was moved to living cells to perform AFM imaging. AFM images were obtained at contact mode. The scan line was 256 and the sampling point for each scan line was also 256 . The scan rate was $0.3-0.5 \mathrm{~Hz}$ and the scan size was $40-100 \mu \mathrm{m}$. For measuring the cellular mechanical properties, force curves were obtained at the central region of living cells. To make the obtained data comparable, all of the force curves were obtained at the same loading rate and the ramp size of the force curves were $6 \mu \mathrm{m}$. To map the stiffness distributions of local areas on the cell surface, arrays of force curves $(5 \times 5)$ were obtained. To analyze the effects of temperature on cell mechanics, force curves were first obtained on $10-15$ cells at room temperature $\left(25^{\circ} \mathrm{C}\right)$. Then the sample stage was heated to $37^{\circ} \mathrm{C}$ and a new cell sample was placed on the stage. Force curves were obtained on 10-15 cells from the new sample. For each cell, 10-15 force curves were obtained at different points on the central region of the cell. To analyze the effects of cellular interactions on cell mechanics, force curves were obtained on 10-15 cells (MCF-7, HeLa and A549) which were co-cultured with Raji or Jurkat cells at $37^{\circ} \mathrm{C}$. Then force curves were obtained on $10-15$ cells from the control group (without Raji or Jurkat cells) at $37^{\circ} \mathrm{C}$. For each cell, $10-15$ force curves were obtained at the different points on the central region of the cell. Before each measurement, the deflection sensitivity and spring constant of the cantilever were calibrated.

\subsection{Data analysis}

Sneddon-modified Hertz model was used to calculate the cellular Young's modulus from the force curves $[16,17]$

$$
F=\frac{2 E \delta^{2} \tan \theta}{\pi\left(1-v^{2}\right)}
$$

where $v$ is the Poisson ratio of cell ( $v=0.5$ for cells as cells are assumed to be incompressible materials), $\delta$ is the depth of indentation, $\theta$ is the half-opening angle of the AFM tip, $E$ is the cellular Young's modulus, and $F$ is the applied loading force. The original force curves were exported as text files via the offline software Nanoscope Analysis (Bruker, USA). Then the text files were processed by the software Matlab. The algorithm of applying Sneddon-Hertz model to calculate the Young's modulus from force curves was programmed using Matlab. Gaussian fitting was applied to fit the statistical histograms of cellular Young's moduli. To map the stiffness distributions of the local areas on the cell surface, arrays of force curves $(5 \times 5)$ were obtained. Each force curve corresponds to a Young's modulus value by applying the Sneddon-Hertz model. After normalizing the Young's moduli into gray colors (0-255), the stiffness maps were constructed by using imaging process software.

\section{Results}

\subsection{Stiffness distributions on the local areas of living cells}

Figure 2 shows obtaining the Young's modulus of living cells from the force curves. Figure $2 \mathrm{~A}$ is a typical force curve obtained on living cells. During the process of obtaining a force curve, the tip first approached and then withdrew from the cells. The approach curve was used for calculating the cellular Young's modulus, while the retract curve was used for calculating the adhesion force [18]. Before the tip contacted the cells, the curve was flat. After the tip contacted the cells, the curve became bent. According to 



Figure 2 Measuring the Young's modulus of living cells from the force curves recorded on the cell surface. A, A typical force curve obtained on living cells. The inset is the contrast of indentation curve and Hertz fitting. The blue arrow denotes the direction of approaching process. The red arrow denotes the direction of withdrawing process. B, AFM topography image of A549 living cells. C, A stiffness map of the local area on the cell denoted by the square in B. Stiffness map was constructed by obtaining $5 \times 5$ force curves in the local area $\left(250 \mathrm{~nm}^{2} \times 250 \mathrm{~nm}^{2}\right)$ of the cell.

the contact point, the approach curve was converted into the indentation curve (the indentation depth was obtained by subtracting the deflection of cantilever from the vertical movement of AFM piezoelectric driver). Then Hertz fitting was applied on the indentation curve to obtain the Young's modulus. The inset in Figure 2A is the contrast of indentation curve and Hertz fitting. We can see that they are consistent with each other, indicating that Hertz model is adequate for characterizing the indenting process between AFM tip and living cells. Figure $2 B$ is the AFM topography image of living A549 cells. After recording $5 \times 5$ force curves at the central region on the cell surface, we can obtain the maps which reflect the stiffness distributions on the cell, as shown in Figure 2C. In order to statistically characterize the stiffness distributions of local areas on living cells, force curves were obtained on about 10 cells with five probes and the stiffness maps were shown in Figure 3. From the stiffness maps (Figures 2C and 3), we can see that the stiffness was variable for the different points on the cell surface. We know cell membrane is highly heterogeneous in composition (an important factor causing this heterogeneity is the existing of lipid rafts [19]), which causes that the obtained stiffness maps are heterogeneous.

We then measure the cellular Young's modulus at different parts on the cell surface (Figure 4). Figure 4A is the AFM image of MCF-7 living cells. Force curves were obtained at the nucleus area (denoted by the red asterisk in Figure 4A) and peripheral area (denoted by the black asterisk in Figure 4A) on one cell. The histograms (Figure 4B and C) of Young's modulus calculated from the force curves show that the nucleus area $(1.88 \mathrm{kPa})$ is softer than peripheral area $(2.88 \mathrm{kPa})$. Then the Young's modulus between nucleus area and lamellipodium area was compared. Figure 4D is the AFM image of another MCF-7 living cells. Force curves were obtained at nucleus area (denoted by the red asterisk in Figure 4D) and lamellipodium area (denoted by the black asterisk in Figure 4D) on one cell. The histograms (Figure 4B and C) of Young's modulus clearly show that the nucleus area $(3 \mathrm{kPa})$ is remarkably softer than la-
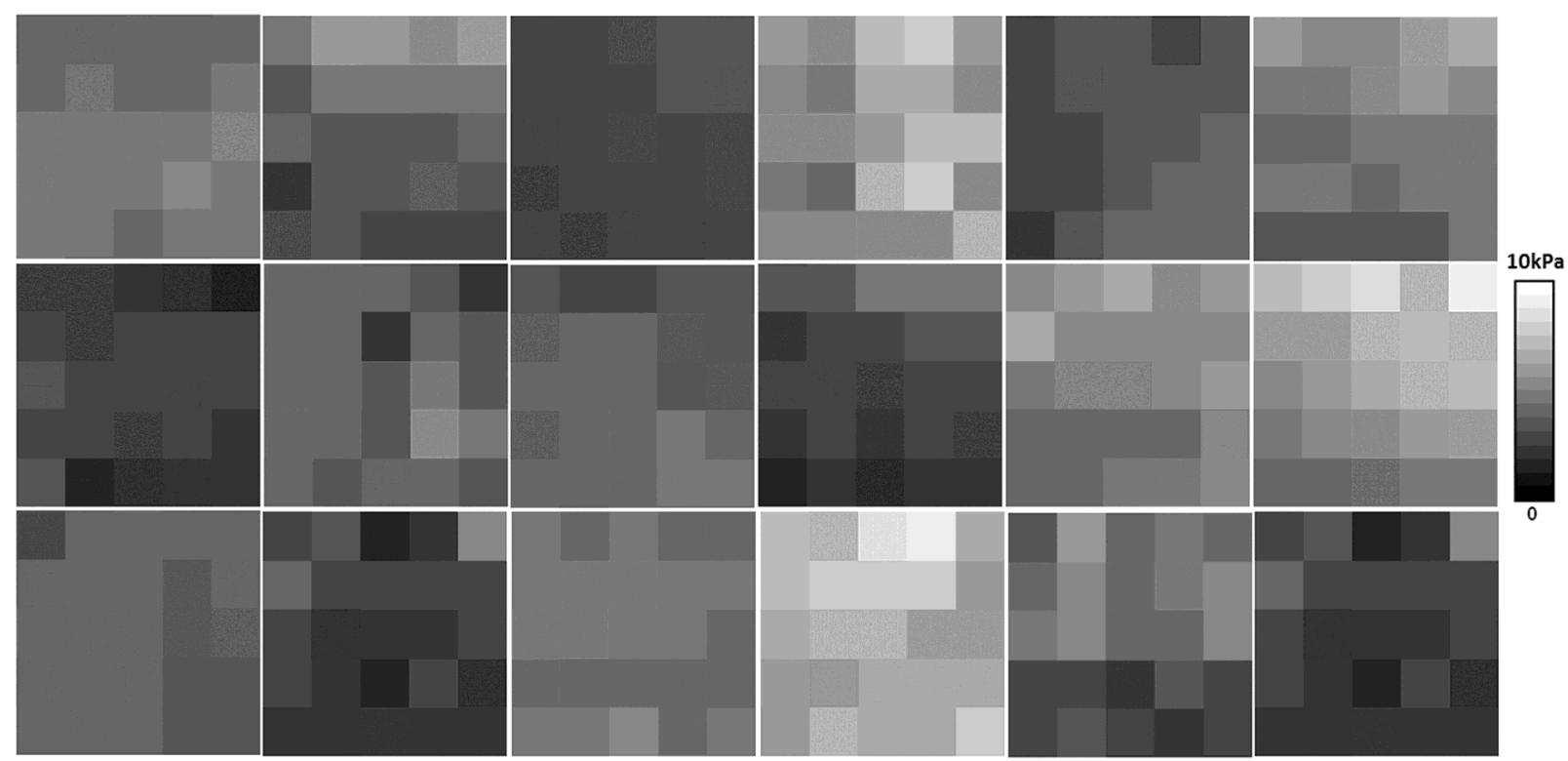

Figure 3 Stiffness maps of different local areas on the living A549 cells. Data were obtained using five probes on about 10 living cells. 

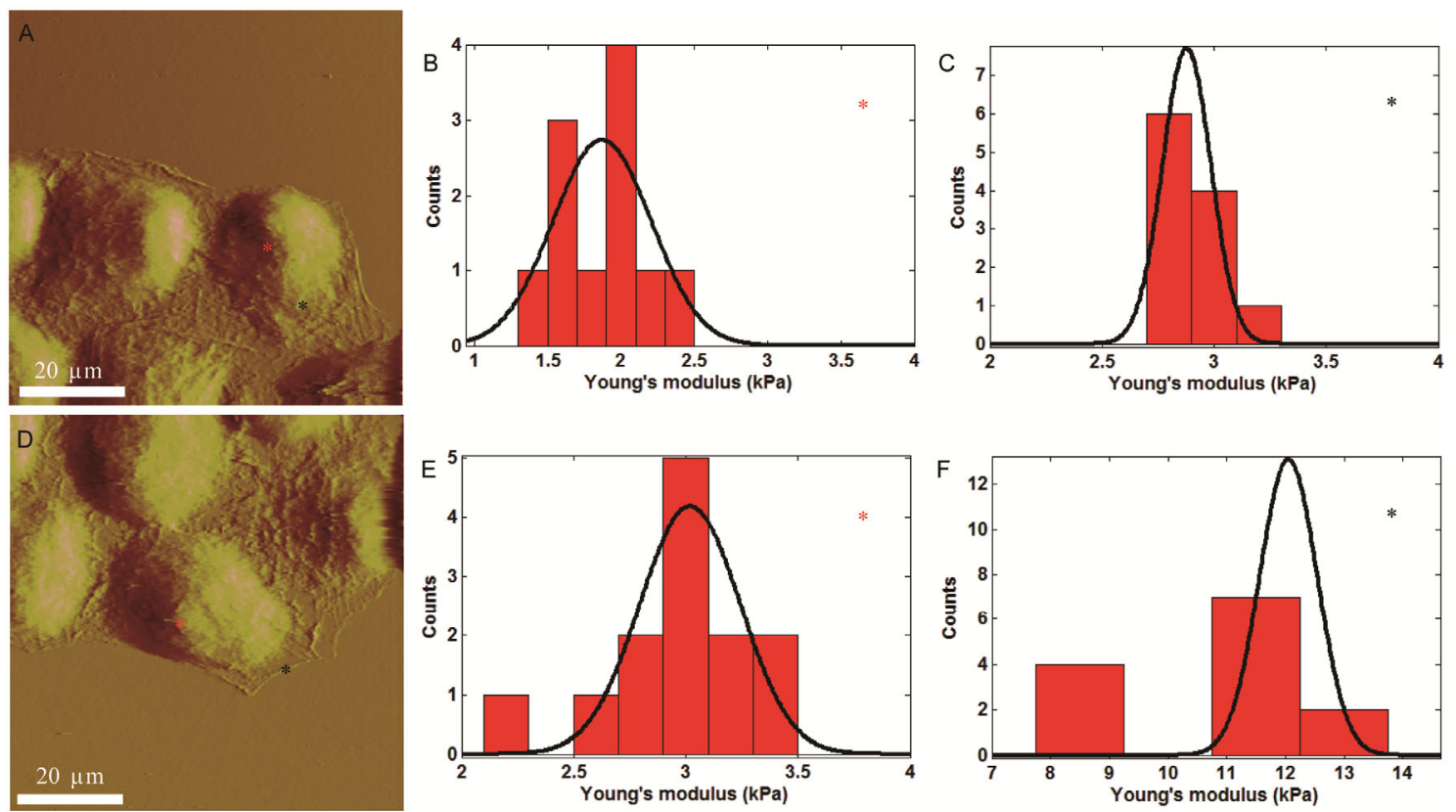

Figure 4 Measuring the Young's modulus at different parts on living cells. A and D, AFM image of MCF-7 cells. B and C, The histograms of cellular Young's modulus measured on nucleus area (B) and peripheral area (C), denoted by the red and black asterisks respectively in (A). E and F, The histograms of cellular Young's modulus measured on nucleus area $(\mathrm{E})$ and lamellipodium area $(\mathrm{F})$, denoted by the red and black asterisks respectively in D.

mellipodium area $(12.1 \mathrm{kPa})$. The results in Figure 4 indicate that the Young's modulus of cellular nucleus area is obviously smaller than other areas on the cell surface. This is because the Young's modulus obtained by AFM is influenced by the rigid substrate [20]. The thickness of the nucleus area is significantly larger than that of the peripheral and lamellipodium areas, causing that the peripheral and lamellipodium areas are more prone to be influenced by the rigid substrate. In order to maximally eliminate the influence of substrate, the indentations should be no more than $10 \%$ of the thickness of the cell. For this reason, in practice force curves are often obtained at the nucleus region of the cell [21]. Besides, studies have shown that the prolonged poking of single cells (200 s) by AFM tip can result in the remodeling of the cell cytoskeleton which can then cause the changes of cellular mechanical properties [22]. Thus we should limit the probing time during the measurements to avoid this effect. For this reason, we only recorded 10-15 force curves on each cell. Altogether, in order to better represent the cellular mechanical properties, for each cell in the following experiments 10-15 force curves were obtained at different points on the nucleus area of the cell.

\subsection{The effects of temperature on the mechanics of human suspended cells}

Currently the AFM indenting experiments are commonly performed at room temperature $[10,23]$ or $37^{\circ} \mathrm{C}[9,21]$. In order to analyze the effects of temperature on cell mechanics, we measured the cellular Young's modulus both at room temperature and $37^{\circ} \mathrm{C}$. We first investigated the effects of temperature on the mechanics of human suspended cells. Three types of human suspended cells (Raji, Jurkat, and normal white blood cells) were used. Figure 5 shows the Young's modulus of Raji, Jurkat and normal white blood cells at room temperature and $37^{\circ} \mathrm{C}$. We can see that the Young's modulus of Raji cells increased from $(2.29 \pm 0.67) \mathrm{kPa}$ to $(3.46 \pm 0.83) \mathrm{kPa}$ as the temperature increased from room temperature to $37^{\circ} \mathrm{C}$. The stiffness distribution of Jurkat cells at room temperature was bimodal $((1.37 \pm 0.55)$ and $(2.72 \pm 0.46) \mathrm{kPa})$. When the temperature increased to $37^{\circ} \mathrm{C}$, the stiffness distribution became unimodal $((0.95 \pm 0.28) \mathrm{kPa})$, showing that the Jurkat cells became softer as the temperature increased. The Young's modulus of normal white blood cells measured at room temperature $((3.17 \pm 1.23) \mathrm{kPa})$ was slightly larger than the Young's modulus measured at $37^{\circ} \mathrm{C}((2.68 \pm 1.24) \mathrm{kPa})$. The results in Figure 5 showed that the degree of mechanical changes in Raji cells and Jurkat cells was clearly larger than that of normal peripheral white blood cells. Raji and Jurkat cells were cancer cells of the hematopoietic system, while normal white blood cells were healthy cells. It is known the structures and functions of cancer cells are quite different from that of normal cells [24]. Hence these difference may cause that cancer cells and normal cells have different mechanical responses to the changes of temperature. Besides, Raji cells were from human lymphoma B cell line and Jurkat cells were from human leukemic $\mathrm{T}$ cell line. The difference between cancer types may cause the different mechanical responses to the changes of temperature. 

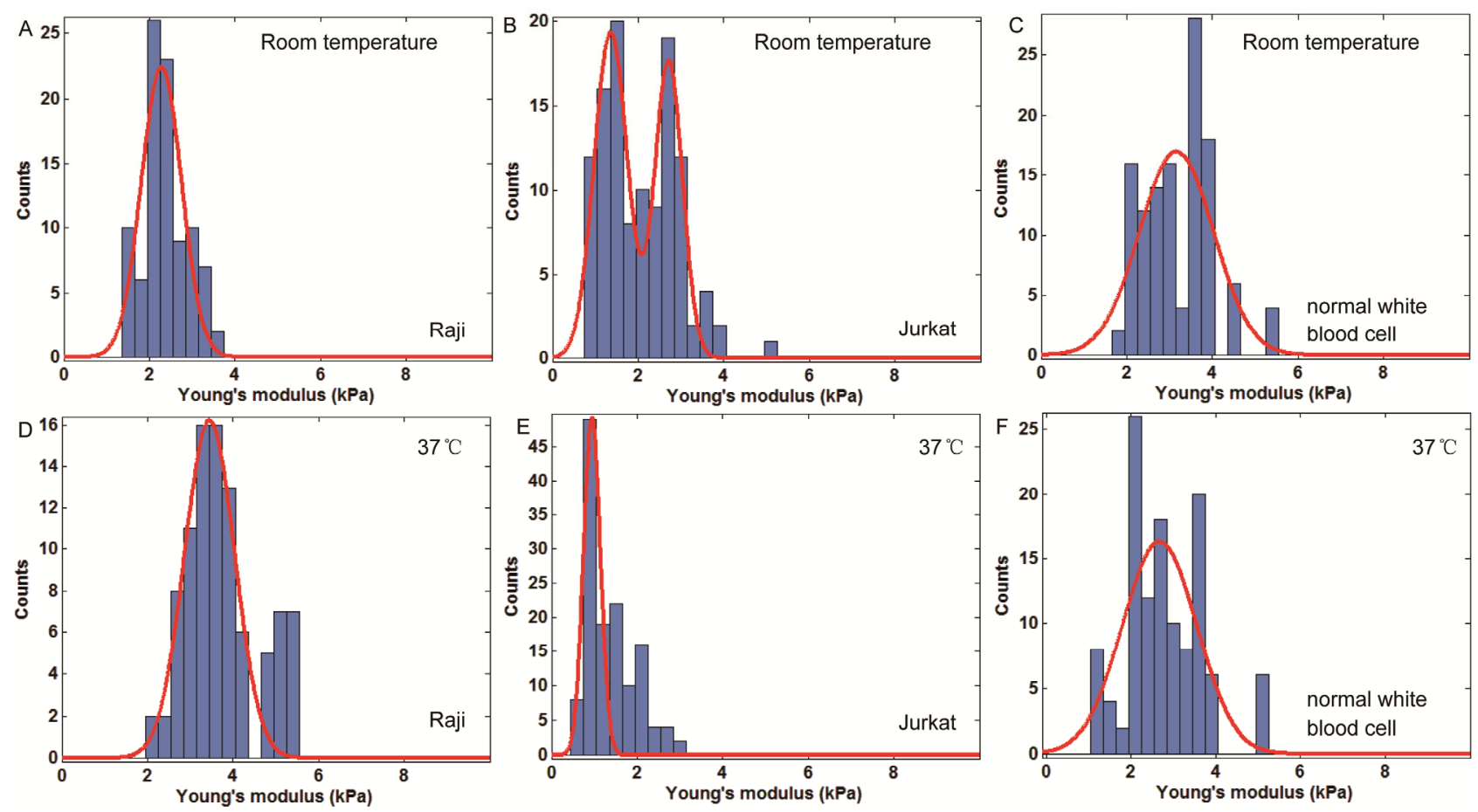

Figure 5 The effects of temperature on the mechanics of human Raji, Jurkat and normal peripheral while blood cells. The Young's modulus histograms of Raji (A), Jurkat (B) and peripheral normal while blood cells (C) obtained at room temperature. The Young's modulus histograms of Raji (D), Jurkat (E) and normal peripheral while blood cells $(\mathrm{F})$ obtained at $37^{\circ} \mathrm{C}$.

\subsection{The effects of temperature on the mechanics of human adherent cells}

In order to examine the effects of temperature on more types of cells, we then measured the Young's modulus of human adherent cells at room temperature and $37^{\circ} \mathrm{C}$. Three types of human adherent cells (MCF-7, HeLa, and A549) were used. The three types of cells were all cancer cell lines. Figure 6 shows the effects of temperature on the mechanics of MCF-7, Hela, and A549 cells. The stiffness distribution of MCF-7 cells at room temperature was bimodal $((2.05 \pm 0.49)$ and $(3.57 \pm 0.36) \mathrm{kPa})$ and the magnitude of the two peaks was similar. When the temperature increased to $37^{\circ} \mathrm{C}$, the stiffness distribution was still bimodal $((2.01 \pm$ $0.30)$ and $(3.6 \pm 1.02) \mathrm{kPa})$. But the magnitude of the second peak $((3.6 \pm 1.02) \mathrm{kPa})$ was clearly smaller than that of the first peak $((2.01 \pm 0.30) \mathrm{kPa})$, indicating that the increase of temperature can cause the softening of MCF-7 cells. For HeLa cells, the Young's modulus increased from (2.14 \pm $0.68) \mathrm{kPa}$ to $(4.3 \pm 3.09) \mathrm{kPa}$ when the temperature increased from room temperature to $37^{\circ} \mathrm{C}$. For A549 cells, the Young's modulus at room temperature $((2.09 \pm 1.32) \mathrm{kPa})$ was a little larger than the Young's modulus at $37^{\circ} \mathrm{C}$ $((1.85 \pm 1.27) \mathrm{kPa})$. Combining the results of Figures 5 and 6 , we can see that different types of human cancer cells (including adherent cells and suspended cells) can have different mechanical responses to the changes of temperature: as the temperature increases some types of cells (Jurkat, MCF-7) become softer, some types of cells (Raji, HeLa) become stiffer, and some types of cells (normal white blood cell, A549) nearly keep invariant.

\subsection{The effects of temperature on cellular morphology}

We know cellular structures (such as cytoskeletons [25]) determine the cellular mechanical properties. Thus, it is reasonable to assume that the changes of cellular mechanical properties are due to the alterations of cellular structures. For this reason, we imaged the living cells (HeLa, A549, MCF-7) both at room temperature and $37^{\circ} \mathrm{C}$ to observe the morphological changes. Figure 7 shows the AFM morphology images of HeLa, A549, and MCF-7 living cells at room temperature and $37^{\circ} \mathrm{C}$. Figure $7 \mathrm{~A}$ and $\mathrm{B}$ are the AFM images of living HeLa cells obtained at room temperature and $37^{\circ} \mathrm{C}$ respectively. From the AFM images, we can see that the cellular topography obtained at $37^{\circ} \mathrm{C}$ was smoother than that obtained at room temperature. Figure $7 \mathrm{C}$ is the profile images along the dashed lines in Figure 7A and B. We can see that the cellular heights at room temperature (blue dashed line) were less than $4 \mu \mathrm{m}$. When the temperature increased to $37^{\circ} \mathrm{C}$ (red dashed line), the heights of two cells were larger than $4 \mu \mathrm{m}$ and the height of the third cell was less than $4 \mu \mathrm{m}$. We measured the heights of $\sim 15 \mathrm{HeLa}$ cells at room temperature and $37^{\circ} \mathrm{C}$ respectively to statistically analyze their difference (Figure 7D). From Figure 7D, we can see that on the whole the height of HeLa cells increased as the temperature increased. Then we imaged the topography of A549 cells (Figure 7E and F) and MCF-7 cells (Fig- 

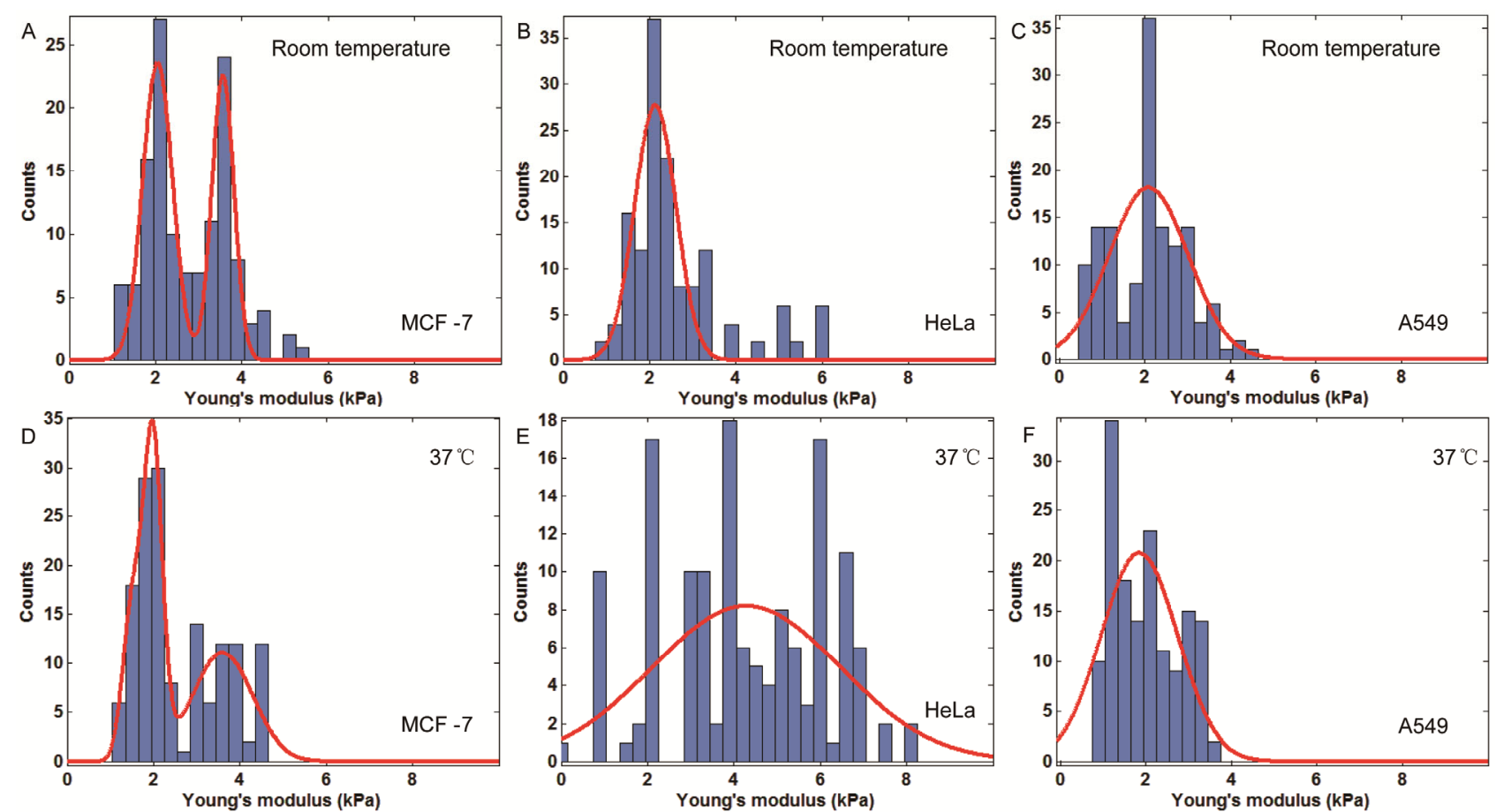

Figure 6 The effects of temperature on the mechanics of human MCF-7, HeLa and A549 cells. The Young's modulus histograms of MCF-7 (A), HeLa (B) and A549 cells (C) obtained at room temperature. The Young's modulus histograms of MCF-7 (D), HeLa (E) and A549 cells (F) obtained at $37^{\circ} \mathrm{C}$.
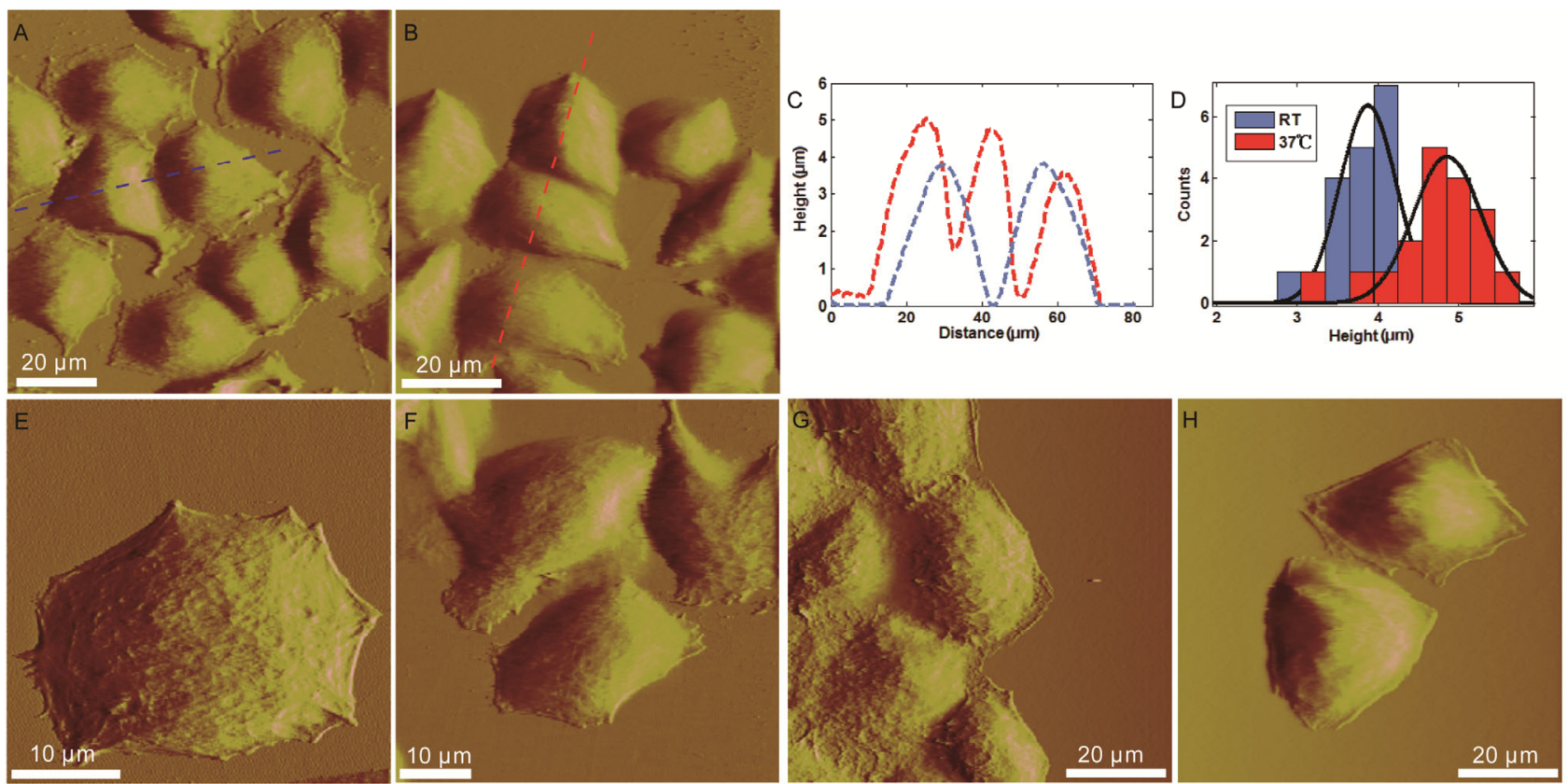

Figure 7 AFM images of living cells obtained at different temperatures. A and B, AFM image of HeLa cells obtained at room temperature (A) and $37^{\circ} \mathrm{C}$ (B). C, Profile images along the dotted lines in A and B. The blue dashed line corresponds to the dashed line in A, and the red dashed line corresponds to the dashed line in B. D, The statistical histogram of cell heights at room temperature and $37^{\circ} \mathrm{C}$. E and F, AFM images of A549 cells obtained at room temperature (E) and $37^{\circ} \mathrm{C}(\mathrm{F}) . \mathrm{G}$ and $\mathrm{H}, \mathrm{AFM}$ images of MCF-7 cells obtained at room temperature $(\mathrm{G})$ and $37^{\circ} \mathrm{C}(\mathrm{H})$.

ure $7 \mathrm{G}$ and $\mathrm{H}$ ) both at room temperature (Figure $7 \mathrm{E}$ and $\mathrm{G}$ ) and $37^{\circ} \mathrm{C}$ (Figure $7 \mathrm{~F}$ and $\mathrm{H}$ ). From Figure $7 \mathrm{E}-\mathrm{H}$, we can obtain the similar conclusion: cell surface became smoother when the temperature increased from room temperature to $37^{\circ} \mathrm{C}$. We have also statistically compared the heights of
A549 and MCF-7 cells at room temperature and $37^{\circ} \mathrm{C}$ (data not shown) and the results showed that cell height became higher when the temperature increased from room temperature to $37^{\circ} \mathrm{C}$. These results indicate that the temperature can cause the changes of cellular structures (such as cell surface, 
cell height), which may then lead to the changes of cellular mechanical properties. However, it should be noted that we only imaged the morphological changes on three types of adherent cells. Adherent cells can grow and spread on the substrate, which facilitates visualizing their morphology by AFM imaging. Human suspended cells (such as Raji, Jurkat) cannot naturally adhere to the substrate. Thus, we need to firstly immobilize them onto the substrate (e.g., via micro-fabricated pillars [26] or polydimethylsiloxane (PDMS) stamp wells [27]) and then we may image their morphology. Besides, the cell cytoskeletons directly determine the cellular mechanical properties. Hence, it is of significance to compare the changes of cell cytoskeletons at room temperature and $37^{\circ} \mathrm{C}$. In this case, strategies such as combining AFM and fluorescence labeling [28] are helpful. Altogether, in the future, studies on more different types of cells (especially suspended cells) are needed to further examine the effects of temperature on cellular morphology.

\subsection{The effects of cellular interactions on the mechan- ics of human cancer cells}

Tumor formation involves the co-evolution of cancer cells together with extracellular matrix, tumor vasculature and immune cells [15]. Recent studies have shown that systematic dissection of interactions between tumors and their micro-environments can uncover important mechanisms underlying drug resistance [29]. The complicated interactions between cancer cells and other cells (e.g., stromal cells, vascular endothelial cells and immune cells) in the micro-environments may cause biochemical or biophysical changes in cancer cells. For this reason, we investigated the interactions between cancer cells and immune cells from the perspective of cell mechanics. Three types of human cancer cells (MCF-7, HeLa, A549) were used. Raji cells and Jurkat cells originate from human lymphocytes and thus it is adequate to use them as immune cells. Figure 8 shows the optical images of human cancer cells co-cultured with human immune cells. Figure 8A and D are the optical images of Raji cells and Jurkat cells respectively. Raji cells and Jurkat cells are suspended cells and they exhibit round shapes in the culture medium. Figure 8B and E are the optical images of A549 cells and MCF-7 cells respectively. A549 and MCF-7 cells are adherent cells and we can see that they adhere and spread on the substrate. HeLa cells are also adherent cells and the optical images of HeLa cells are not shown. When co-culturing adherent cells with suspended cells, we can easily discern them according to their special shapes. Figure $8 \mathrm{C}$ is the optical image of A549 cells co-cultured with Raji cells. Figure $8 \mathrm{~F}$ is the optical image of MCF-7 cells co-cultured with Jurkat cells. In the images (Figure 8C and F), Raji and Jurkat cells were clearly recognized according to their round shapes (denoted by the dashed circles).

After 24-h co-culture, the Young's moduli of cancer cells with and without immune cells were measured, as shown in Figure 9. The results of Figures 5 and 6 showed that the temperature can cause the changes of mechanical properties,
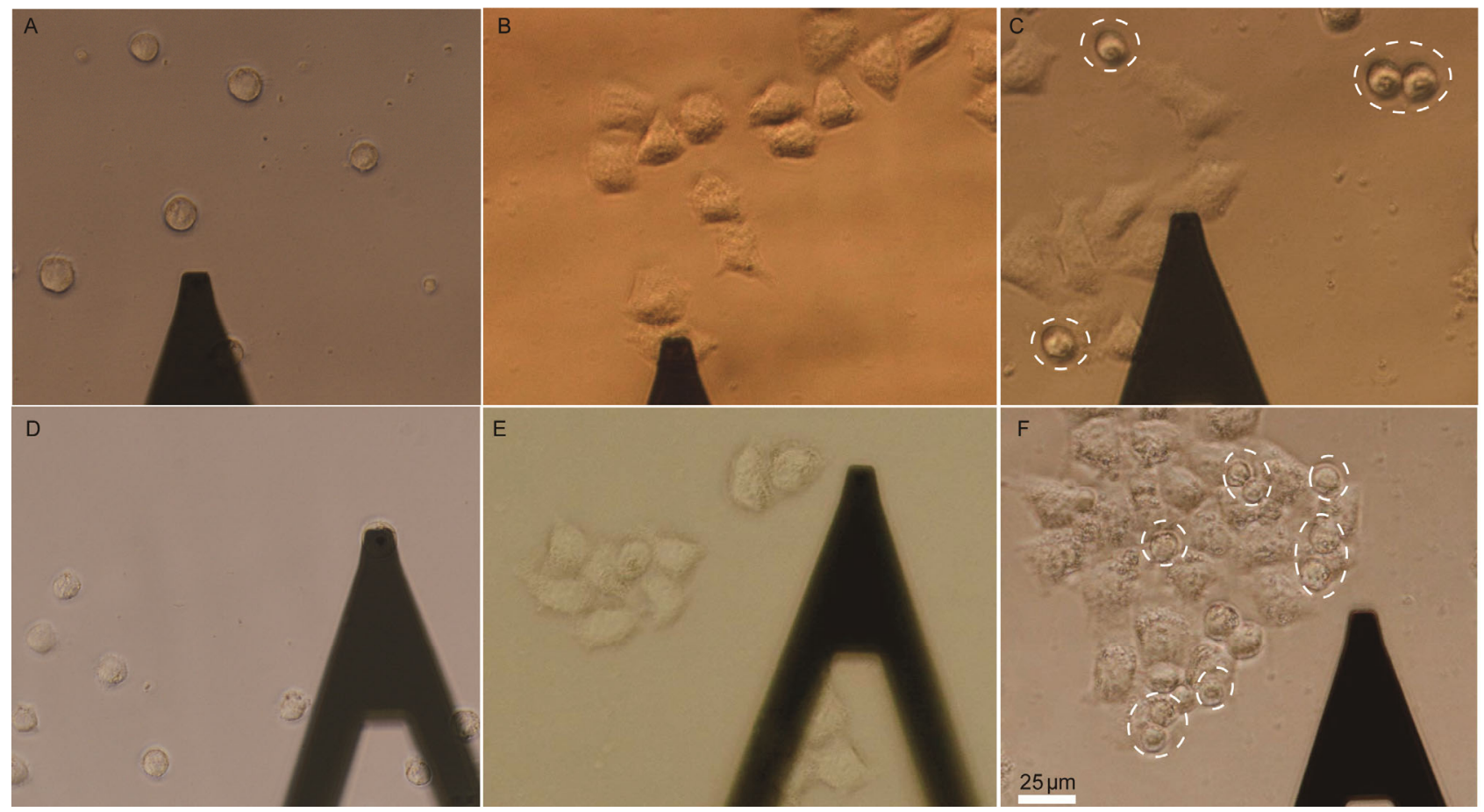

Figure 8 Optical images of human cancer cells co-cultured with human immune cells. A-C, Optical images of Raji cells (A), A549 cells without Raji cells (B), and A549 cells with Raji cells (C). D-F, Optical images of Jurkat cells (D), MCF-7 cells without Jurkat cells (E), and MCF-7 cells with Jurkat cells (F). The dashed circles in C denote the Raji cells and the dashed circles in F denote the Jurkat cells. 

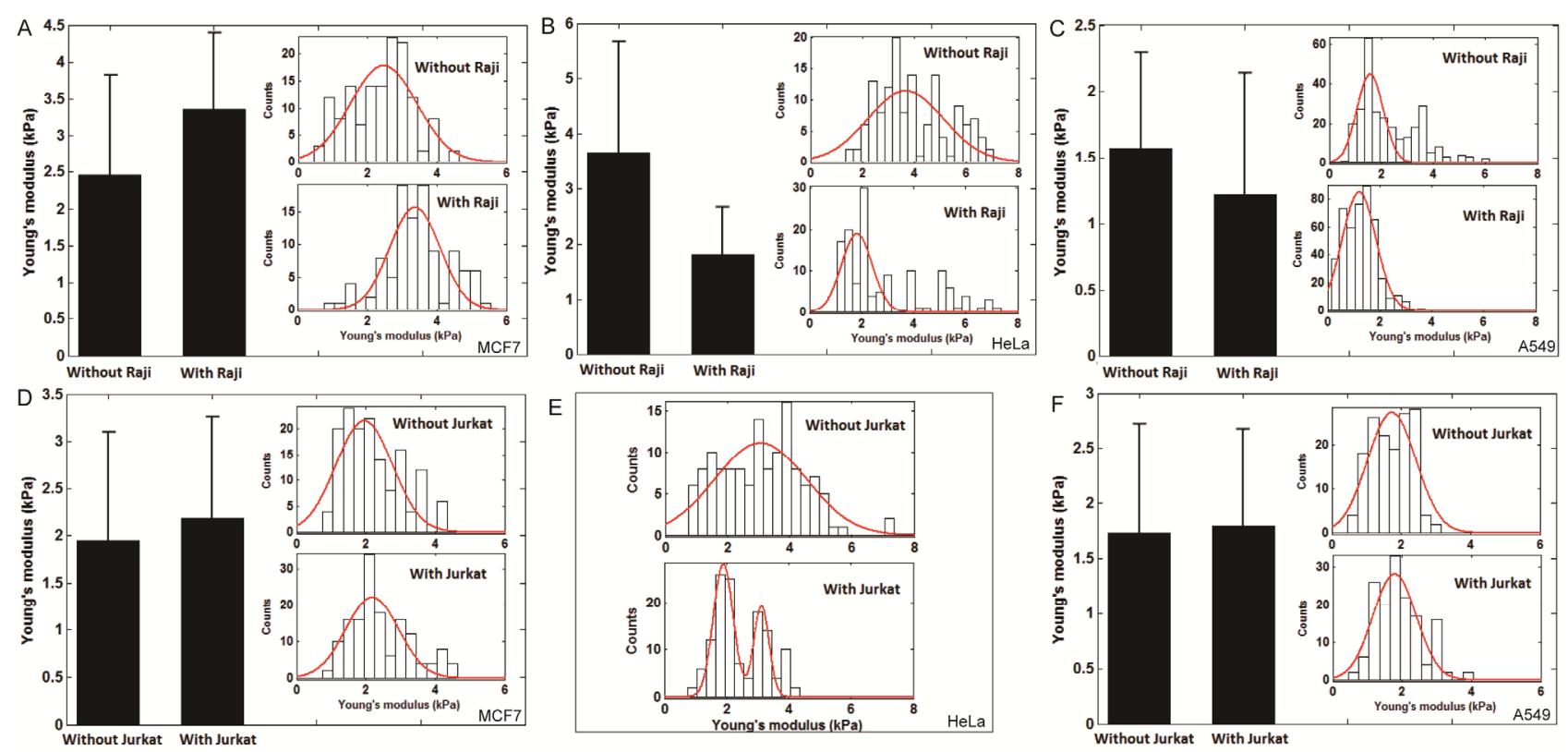

Figure 9 (color online) The effects of co-culture on the mechanics of human cancer cells (MCF-7, HeLa, A549). The changes of Young's modulus of MCF-7 cells (A), HeLa cells (B) and A549 cells (C) after being co-culture with Raji cells. The changes of Young's modulus of MCF-7 cells (D), HeLa cells (E) and A549 cells (F) after being co-culture with Jurkat cells. The insets are the histograms of Young's modulus without and with immune cells.

and thus the experiments of measuring the Young's modulus of cancer cells with and without immune cells were carried out at $37^{\circ} \mathrm{C}$ to avoid the influence of temperature. As shown in Figure 9, the Young's modulus of MCF-7 cells increased from $(2.46 \pm 1.36) \mathrm{kPa}$ to $(3.36 \pm 1.03) \mathrm{kPa}$ after being co-cultured with Raji cells. While the Young's modulus of HeLa cells decreased from $(3.67 \pm 2.01) \mathrm{kPa}$ to $(1.82 \pm 0.84) \mathrm{kPa}$ after being co-cultured with Raji cells. The Young's modulus of A549 cells grown with Raji cells $((1.22 \pm 0.92) \mathrm{kPa})$ was slightly smaller than that grown without Raji cells $((1.57 \pm 0.72) \mathrm{kPa})$. After being cocultured with Jurkat cells, the Young's modulus of MCF-7 cells increased from $(1.95 \pm 1.15) \mathrm{kPa}$ to $(2.18 \pm 1.08) \mathrm{kPa}$. While the Young's modulus of A549 cells kept unchanged. The Young's modulus of HeLa cells was $(3.07 \pm 2.11) \mathrm{kPa}$ grown without Jurkat cells. After being co-cultured with Jurkat cells, the stiffness distribution of HeLa cells became bimodal $((1.9 \pm 0.45),(3.13 \pm 0.35) \mathrm{kPa})$, showing that some HeLa cells $((1.9 \pm 0.45) \mathrm{kPa})$ became softer. We can see that the co-culture of cancer cells and immune cells can cause the stiffening (Raji+MCF-7, Jurkat+MCF-7), softening (Raji+HeLa, Jurkat+HeLa, Raji+A549), or no significant mechanical changes (Jurkat+A549) in cancer cells. On the whole, the results in Figure 9 showed that the co-culture of cancer cells and immune cells can alter the mechanical properties of cancer cells and the mechanical changes depended on the types of cancer cells and immune cells.

\subsection{The effects of cellular interactions on the mor- phology of human cancer cells}

In order to examine whether the co-culture of human cancer cells and human immune cells can influence the cell morphology, AFM images of living cancer cells grown without and with immune cells were obtained, as shown in Figure 10. In order to avoid the influence of temperature, images were obtained at $37^{\circ} \mathrm{C}$. Figure $10 \mathrm{~A}, \mathrm{C}$ and $\mathrm{E}$ are the typical AFM images of cancer cells grown without immune cells and Figure 10B, D and F are the typical AFM images of cancer cells grown with immune cells. From the AFM images, we cannot observe the distinct morphological changes in cancer cells after being co-cultured with immune cells. Cell heights were quantitatively analyzed and the results (data not shown) showed that there were no significant differences in cell heights between the cancer cells with and without immune cells. When co-culturing cancer cells with immune cells for $24 \mathrm{~h}$, the interactions between cancer cells and immune cells can cause the mechanical changes of cancer cells (Figure 9) but do not cause the morphological changes (Figure 10). We know the cellular mechanical properties are related to many factors, such as cell membrane, cytoskeleton, cytoplasm and cellular nucleus [30,31]. It was likely that during the co-culture the morphology of cancer cells kept unchanged but some changes (such as cell nucleus, cell cytoskeleton) inside the cancer cells occurred. These changes then caused the alterations of cellular mechanical properties. The results in Figures 9 and 10 showed that though no significant morphological differences could be observed among cancer cells with and without immune cells, observable differences in cellular mechanical properties could be detected. 

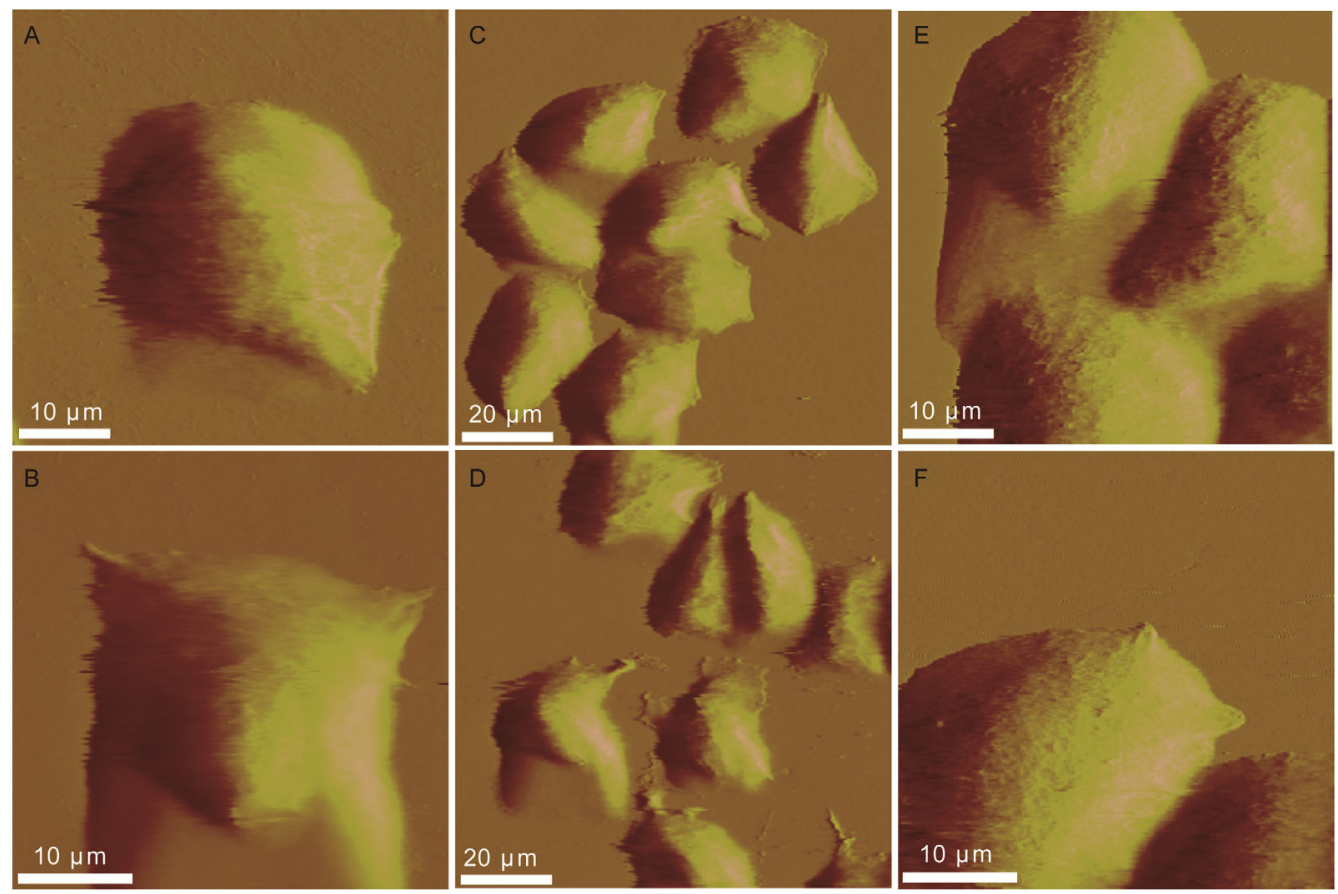

Figure 10 AFM images of living human cancer cells (MCF-7, HeLa, A549) grown with and without immune cells (Raji, Jurkat). A and B, AFM images of MCF-7 cells grown without (A) and with (B) Raji cells. C and D, AFM images of HeLa cells grown without (C) and with (D) Jurkat cells. E and F, AFM images of A549 cells grown without (E) and with (F) Raji cells.

\section{Discussion}

AFM is a powerful tool for quantifying the mechanics of single living cells in aqueous conditions. By obtaining arrays of force curves at the local areas, the stiffness distributions on the nucleus areas of living A549 cells were mapped. The maps (Figures 2C and 3) showed that the stiffness distributions of the cell surface were heterogeneous. When performing small-size (such as less than $1 \mu \mathrm{m}$ ) AFM imaging on living mammalian cells, it is difficult to obtain high-quality images due to the soft and dynamic nature of cell surfaces $[32,33]$. Besides, in the AFM images the texture of cellular surface was almost the same for one cell (excepting the cellular edges), as shown in Figures 7 and 10. These cause that we often cannot visually discern the different nanostructures on the cell surface from AFM images. In contrast, stiffness maps can reveal the different nanoscale areas on the cell surface from the perspective of mechanics, which is useful for us to understand the sub-cellular structures of living cells. However, AFM is label-free and thus we do not know the nanoscale areas in the stiffness maps correspond to which components of the cells. If AFM is combined with single-molecule fluorescence microscopy [34], we can then directly investigate the relationship between mechanical information and cell structures. AFM and fluorescence can provide complementary information, which is of great significance for us to explore the underlying mechanisms that regulate the structure and mechanics of living cells during cellular physio- logical activities. The indenting experiments at different areas on living cells (Figure 4) showed that the Young's modulus of nucleus areas was significantly smaller than other areas (such as peripheral areas and lamellipodium areas), inspiring us to quantify the cell mechanics on the nucleus area to reduce the effect of rigid substrate.

The cellular Young's modulus obtained from AFM indenting measurements is a relative value and can be used for comparative studies in cases when all experimental conditions are identical [12]. Some factors that influence the cellular Young's modulus have been widely known, such as the loading rate, the indentation depth, the substrate, and the AFM probe (e.g., the shape of the tip, the spring constant of the cantilever). However, there are still factors that have been neglected. For example, studies have shown that the growth medium can influence the cellular Young's modulus [35]. Here all of the cells were cultured with the same cell growth medium to avoid the influence of cell growth medium. Besides, the temperature can also influence the cell mechanics [13,14,36,37]. Rico et al. [13] have measured the Young's modulus of THP-1 cells (human monocytic leukemia cell line) at three temperatures (16, 24 and $37^{\circ} \mathrm{C}$ ), showing that the cellular Young's modulus significantly decreased as the temperature increased. Spedden et al. [14] have measured the Young's modulus of neuron cells prepared from embryonic rat at room temperature $\left(25^{\circ} \mathrm{C}\right)$ and $37^{\circ} \mathrm{C}$, also showing that the increase of temperature can cause the cell softening. However, other scholars [36,37] have obtained the opposite results. Sunyer 
et al. [36] have measured the Young's modulus of human alveolar epithelial cells at different temperatures $\left(13-37^{\circ} \mathrm{C}\right)$, showing that the increasing temperature can make cells become stiffer and more solid-like. Codan et al. [37] have compared the Young's modulus of 3T3 cells (mouse embryonic fibroblasts) and SW-13 cells (human epithelial cancer cells) at different temperatures, showing that both of the two types of cells had an decreased Young's modulus as the temperature decreased. In this article, we quantitatively investigated the effects of temperature on six types of cells (including three types of human suspended cells and three types of human adherent cells). In order to eliminate the artificial effects and make the results comparative, several strategies were adopted, e.g., force curves were obtained at the same loading rate, the indentation curves used for Young's modulus calculation were less than $500 \mathrm{~nm}$, and force curves were obtained at the different points on the central areas of cells. Our results (Figures 5 and 6) showed that different types of cells can have different mechanical responses to the changes of temperature: some cells (Raji and HeLa cells) became stiffer as the temperature increased, some cells (Jurkat and MCF-7 cells) became softer as the temperature increased, and some cells (normal peripheral white blood cells and A549 cells) kept stable as the temperature changed. AFM imaging of living cells at room temperature and $37^{\circ} \mathrm{C}$ (Figure 7) showed that the changes of temperature can cause the significant morphological changes of cells: cell height became higher and cell surface became smoother as the temperature increased from room temperature to $37^{\circ} \mathrm{C}$. We know that the cellular mechanical properties are determined by the cell cytoskeletons [25]. Studies have shown that the changes of temperature can cause the reorganization of actin components of the cytoskeletons which then resulted in the changes of cellular Young's modulus [14]. Hence, it is reasonable that the morphological changes (Figure 7) observed here were due to the reorganization of cell cytoskeletons.

Current AFM indenting experiments were commonly performed at one temperature (at room temperature or at $37^{\circ} \mathrm{C}$ ) to investigate the cellular mechanical properties during physiological activities (such as observing the changes of cellular mechanical properties after the stimulation of drugs). From the results in this article, we can conclude that the responses of cellular mechanical properties to the changes of temperature are not a universal phenomenon and different types of cells can have different responses (stiffening, softening or invariant) to the changes of temperature. The results inspire us that we can measure the mechanical properties of cells at different temperatures to construct the stiffness profiles, like the Raman spectra of the different materials. Because different types of cells (such as cancer cells and normal cells) can respond differently to the changes of temperature, we may discern the different types of cells according to their stiffness profiles. We know AFM detection has several advantages compared with traditional biochemical methods, such as it is label-free, with low cost and the detection speed is fast. If we can exactly recognize the different types of cells in a mixed cell populations (such as the circulating tumor cells in the blood) by measuring their stiffness using AFM, it will greatly improve our current studies of single living cells and will bring novel insights into cell biology. In this article, we used conical tips to perform the indenting experiments. The conical tips are sharp and they measure the mechanical properties of local areas on the cell surface. In recent years, researchers have used sphere tips to quantify the mechanical properties of the whole living cells [16,35,38,39]. Compared with conical tips, sphere tips have larger contact areas and thus smaller applied pressures, causing that cellular Young's modulus measured with sphere tips is less than that with conical tips [40]. Despite this difference, the studies by Rico et al. [41] have showed that the change trend of cellular Young's modulus measured using sphere tips was consistent with that using conical tips. Besides, Cross et al. [21] and Li et al. [42] measured the Young's modulus of different cells (cancer cells and normal cells) using conical tips and sphere tips respectively and they obtained the coincident results. Hence, the results obtained using conical tips are basically consistent with that using sphere tips.

Immune cells that infiltrate tumors engage in an extensive and dynamic crosstalk with cancer cells, which plays important roles at different stages of tumor development, including initiation, promotion, malignant conversion, invasion, and metastasis [43]. During the formation of solid tumors, cancer cells interact with various types of normal cells (e.g., immune cells, stromal cells) in the microenvironment. The heterogeneous types of cells in the microenvironment of tumors and their interactions with cancer cells can influence the therapeutic response and drug resistance [15]. Hence, investigating the interactions between cancer cells and the other cells in the micro-environment is of great significance for both uncovering the underlying mechanisms of cancer heterogeneity and improving the clinical treatments of cancer patients. Studies of tumorinfiltrating immune cells in large cohorts of human colorectal cancers have shown that the type, density, and location of immune cells within human tumors can be used to predict the clinical outcome [44]. In fact targeting the tumor micro-environment has become a new treatment strategy of cancers, which will hopefully improve our current therapeutic efforts [45]. Cellular mechanical properties have been proved to be effective label-free biomarkers for indicating cell states. Studies have qualitatively shown that cancer cells are softer than normal cells [8-10]. However, how the physiological activities taking place in the formation of solid tumors dynamically alter the mechanical properties of cancer cells is still an unknown research area. Here we measured the mechanical changes of human cancer cells after being co-cultured with human immune cells. The ex- 
perimental results (Figure 9) showed that the interactions between cancer cells and immune cells can alter the mechanical properties of cancer cells. But the AFM imaging (Figure 10) showed that there were no significant morphological changes after the co-culture. This can be explained that cell morphology is not the solely determinants for cell mechanics. In 2009, Reich et al. [46] have investigated the mechanical properties and morphology of fibroblasts from scleroderma patients and from healthy donors using AFM, showing that the fibroblasts from scleroderma patients were softer than cells from healthy donors but no significant morphological differences could be observed. During the co-culture of cancer cells and immune cells, the morphology of cancer cells did not change, but the cytoskeletons inside the cancer cells might change which resulted in the changes of cell mechanical properties. Currently there is lacking of effective ways to quantitatively understand the molecular and cellular interactions in signal transduction [47]. Our results showed that we can characterize the interactions between cancer cells and other cells from the changes of cell mechanics, providing a novel ideal to quantitatively investigate the interactions between cells. However, it should be noted that the optimal conditions for living cells is $37^{\circ} \mathrm{C}$ with $5 \% \mathrm{CO}_{2}$. In this article, we only provided the $37^{\circ} \mathrm{C}$. The lack of $5 \% \mathrm{CO}_{2}$ condition may cause some changes on the living cells. For this reason, introducing the $5 \% \mathrm{CO}_{2}$ condition can help us to better investigate the cellular mechanical properties during physiological activities. Martens and Radmacher [23] have developed a polymethylmethacrylate (PMMA) box to maintain $5 \% \mathrm{CO}_{2}$ environment, demonstrating the feasibility of measuring the mechanical properties of cells in $37^{\circ} \mathrm{C}\left(5 \% \mathrm{CO}_{2}\right)$ using AFM. Altogether, AFM has proven to be a powerful tool in label-free quantifying the mechanical properties of single living cells. The further applications of AFM will provide more and more novel insights into our understanding of cellular behaviors and diseases.

\section{Conclusion}

This work quantitatively investigated the effects of temperature and cellular interactions on the mechanical and morphological properties of human cancer cells with the use of AFM. Stiffness maps were obtained on living cells by recording arrays of force curves at the local areas, showing that the stiffness distributions on the surface of living cells were heterogeneous. The effects of temperature on cellular mechanics were quantitatively studied on six types of cells (Raji, Jurkat, normal white blood cell, MCF-7, HeLa, A549) at room temperature and $37^{\circ} \mathrm{C}$, showing that different types of cells can have different responses (stiffening, softening or invariant) to the changes of temperature. AFM living cell imaging at different temperatures showed that the changes of temperature can cause the distinct morphological changes of cells (cell surface became smoother and cell height became higher when temperature increased). The effects of cellular interactions on the mechanics of cancer cells were studied on three types of human cancer cells (MCF-7, HeLa, A549) by co-culturing them with two types of human immune cells (Raji, Jurkat), showing that the interactions between cancer cells and immune cells can alter the mechanical properties of cancer cells. While AFM living cell imaging showed that the co-incubation of cancer cells and immune cells did not cause significant morphological changes of cancer cells. In future studies, we plan to further investigate the interactions between cancer cells and other cells (such as stromal cells) from the perspective of mechanics. These studies will be particularly useful for us to understand the role of cellular interactions in the process of tumor formation.

The authors declare that they have no conflict of interest.

This work was supported by the National Natural Science Foundation of China (61175103, 61375107, 61327014, 61433017), the Research Fund of the State Key Laboratory of Robotics (2014-Z07), and CAS FEA International Partnership Program for Creative Research Teams.

1 Suresh S. Biomechanics and biophysics of cancer cells. Acta Biomater, 2007, 3: 413-438

2 Koumoutsakos P, Pivkin I, Milde F. The fluid mechanics of cancer and its therapy. Ann Rev Fluid Mech, 2013, 45: 325-355

3 Lee GY, Lim CT. Biomechanics approaches to studying human diseases. Trends Biotechnol, 2007, 25: 111-118

4 Perrault CM, Bray EJ, Didier N, Ozaki CK, Tran-Son-Tay R. Altered rheology of lymphocytes in the diabetic mouse. Diabetologia, 2004, 47: 1722-1726

5 Trickey WR, Vail TP, Guilak F. The role of the cytoskeleton in the viscoelastic properties of human articular chondrocytes. J Orthop Res, 2004, 22: 131-139

6 Tomioka S, Bates JH, Irvin CG. Airway and tissue mechanics in a murine model of asthma: alveolar capsule vs. forced oscillations. J Appl Physiol, 2002, 93: 263-270

7 Zheng Y, Nguyen J, Wei Y, Sun Y. Recent advances in microfluidic techniques for single-cell biophysical characterization. Lab Chip, 2013, 13: 2464-2483

8 Fritsch A, Hockel M, Kiessling T, Nnetu KD, Wetzel F, Zink M, Kas JA. Are biomechanical changes necessary for tumour progression. Nat Phys, 2010, 6: 730-732

9 Efremov YM, Lomakina ME, Bagrov DV, Makhnovskiy PI, Alexandrova AY, Kirpichnikov MP, Shaitan KV. Mechanical properties of firbroblasts depend on level of cancer transformation. Biochim Biophys Acta, 2014, 1843: 1013-1019

10 Plodinec M, Loparic M, Monnier CA, Obermann EC, ZanettiDallenbach R, Oertle P, Hyotyla JT, Aebi U, Bentires-Alj M, Lim $\mathrm{RY}$, Schoenenberger CA. The nanomechanical signature of breast cancer. Nat Nanotechnol, 2012, 7: 757-765

11 Wirtz D, Konstantopoulos K, Searson PC. The physics of cancer: the role of physical interactions and mechanical forces in metastasis. Nat Rev Cancer, 2011, 11: 512-522

12 Lekka M, Pogoda K, Gostek J, Klymenko O, Prauzner-Bechcicki S, Wiltowska-Zuber J, Jaczewska J, Lekki J, Stachura Z. Cancer cell recognition-mechanical phenotype. Micron, 2012, 43: 1259-1266

13 Rico F, Chu C, Abdulreda MH, Qin Y, Moy VT. Temperature modulation of integrin-mediated cell adhesion. Biophys J, 2010, 99: 
1387-1396

14 Spedden E, Kaplan D, Staii C. Temperature response of the neuronal cytoskeleton mapped via atomic force and fluorescence microscopy. Phys Biol, 2013, 10: 056002

15 Junttila MR, Sauvage FJ. Influence of tumour micro-environment heterogeneity on the therapeutic response. Nature, 2013, 501: 346-354

16 Li M, Liu L Q, Xi N, Wang Y, Dong Z, Xiao X, Zhang W. Atomic force microscopy imaging and mechanical properties measurement of red blood cells and aggressive cancer cells. Sci China Life Sci, 2012, 55: 968-973

17 Li M, Liu L, Xi N, Wang Y, Xiao X, Zhang W. Nanoscale imaging and mechanical analysis of Fc receptor-mediated macrophage phagocytosis against cancer cells. Langmuir, 2014, 30: 1609-1621

18 Li M, Liu L, Xi N, Wang YC. Progress in measuring biophysical properties of membrane proteins with AFM single-molecule force spectroscopy. Chin Sci Bull, 2014, 59: 2717-2725

19 Lingwood D, Simons K. Lipid rafts as a membrane-organizing principle. Science, 2010, 327: 46-50

20 Gavara N, Chadwick RS. Determination of the elastic moduli of thin samples and adherent cells using conical atomic force microscope tips. Nat Nanotechnol, 2012, 7: 733-736

21 Cross SE, Jin YS, Rao J, Gimzewski JK. Nanomechanical analysis of cells from cancer patients. Nat Nanotechnol, 2007, 2: 780-783

22 Lekka M, Laidler P. Applicability of AFM in cancer detection. Nat Nanotechnol, 2009, 4: 72-73

23 Martens JC, Radmacher M. Softening of the actin cytoskeleton by inhibition of myosin II. Pflugers Arch Eur J Physiol, 2008, 456: 95-100

24 Hanahan D, Weinberg RA. Hallmarks of cancer: the next generation. Cell, 2011, 144: 646-674

25 Fletcher DA, Mullins RD. Cell mechanics and the cytoskeleton. Nature, 2010, 463: 485-492

26 Li M, Liu L, Xi N, Wang YC, Dong ZL, Xiao XB, Zhang WJ. Drug-induced changes of topography and elasticity in living B lymphoma cells based on atomic force microscopy. Acta Phys Chim Sin, 2012, 28: 1502-1508

27 Formosa C, Pillet F, Shiavone M, Duval RE, Ressier L, Dague E. Generation of living cell arrays for atomic force microscopy studies. Nat Protoc, 2015, 10: 199-204

28 Kirmse R, Otto H, Ludwig T. Interdependency of cell adhesion, force generation and extracellular proteolysis in matrix remodeling. J Cell Sci, 2011, 124: 1857-1866

29 Straussman R, Morikawa T, Shee K, Barzily-Rokni M, Qian ZR, Du J, Davis A, Mongare MM, Gould J, Frederick DT, Cooper ZA, Chapman PB, Solit DB, Ribas A, Lo RS, Flaherty KT, Ogino S, Wargo JA, Golub TR. Tumour micro-environment elicits innate resistance to RAF inhibitors through HGF secretion. Nature, 2012, 487: 500-504

30 Krause M, Riet J, Wolf K. Probing the compressibility of tumor cell nuclei by combined atomic force-confocal microscopy. Phys Biol, 2013, 10: 065002

31 Moeendarbary E, Valon L, Fritzsche M, Harris AR, Moulding DA, Thrasher AJ, Stride E, Mahadevan L, Charras GT. The cytoplasm of living cells behaves as a poroelastic material. Nat Mater, 2013, 12: 253-261

32 Muller DJ, Dufrene YF. Atomic force microscopy: a nanoscopic window on the cell surface. Trends Cell Biol, 2011, 21: 461-469

33 Li M, Liu L, Xi N, Wang Y, Dong Z, Xiao X, Zhang W. Atomic force microscopy imaging of living mammalian cells. Sci China Life Sci, 2013, 56: 811-817

34 Fukuda S, Uchihashi T, Iino R, Okazaki Y, Yoshida M, Igarashi K, Ando T. High-speed atomic force microscope combined with single-molecule fluorescence microscopy. Rev Sci Instru, 2013, 84: 073706

35 Nikkhah M, Strobl JS, Schmelz EM, Agah M. Evaluation of the influence of growth medium composition on cell elasticity. J Biomech, 2011, 44: 762-766

36 Sunyer R, Trepat X, Fredberg JJ, Farré R, Navajas D. The temperature dependence of cell mechanics measured by atomic force microscopy. Phys Biol, 2009, 6: 025009

37 Codan B, Martinelli V, Mestroni L, Sbaizero O. Atomic force microscopy of 3T3 and SW-13 cell lines: an investigation of cell elasticity changes due to fixation. Mater Sci Eng C Mater Biol Appl, 2013, 33: 3303-3308

38 Lulevich V, Zimmer CC, Hong HS, Jin LW, Liu GY. Single-cell mechanics provides a sensitive and quantitative means for probing amyloid- $\beta$ peptide and neuronal cell interactions. Proc Natl Acad Sci USA, 2010, 107: 13872-13877

39 Li M, Liu L, Xi N, Wang YC. Research progress in quantifying the mechanical properties of single living cells using atomic force microscopy. Chin Sci Bull, 2014, 59: 4020-4029

40 Leporatti S, Gerth A, Köhler G, Kohlstrunk B, Hauschildt S, Donath E. Elasticity and adhesion of resting and lipopolysaccharidestimulated macrophages. FEBS Lett, 2006, 580: 450-454

41 Rico F, Roca-Cusachs P, Gavara N, Farré R, Rotger M, Navajas D. Probing mechanical properties of living cells by atomic force microscopy with blunted pyramidal cantilever tips. Phys Rev E, 2005, 72: 021914

42 Li QS, Lee GY, Ong CN, Lim CT. AFM indentation study of breast cancer cells. Biochem Biophys Res Commun, 2008, 374: 609-613

43 Grivennikov SI, Greten FR, Karin M. Immunity, inflammation, and cancer. Cell, 2010, 140: 883-899

44 Galon J, Costes A, Sanchez-Cabo F, Kirilovsky A, Mlecnik B, Lagorce-Pagès C, Tosolini M, Camus M, Berger A, Wind $\mathrm{P}$, Zinzindohoué F, Bruneval P, Cugnenc PH, Trajanoski Z, Fridman WH, Pagès $F$. Type, density, and location of immune cells within human colorectal tumors predict clinical outcome. Science, 2006, 313: 1960-1964

45 Burger JA, Ghia P, Rosenwald A, Caligaris-Cappio F. The microenvironment in mature B-cell malignancies: a target for new treatment strategies. Blood, 2009, 114: 3367-3375

46 Reich A, Meurer M, Eckes B, Friedrichs J, Muller DJ. Surface morphology and mechanical properties of fibroblasts from scleroderma patients. J Cell Mol Med, 2009, 13: 1644-1652

47 Groves JT, Kuriyan J. Molecular mechanisms in signal transduction at the membrane. Nat Struct Mol Biol, 2010, 17: 659-665

Open Access This article is distributed under the terms of the Creative Commons Attribution License which permits any use, distribution, and reproduction in any medium, provided the original author(s) and source are credited. 